\title{
Article \\ A Chaotic Quadratic Oscillator with Only Squared Terms: Multistability, Impulsive Control, and Circuit Design
}

\author{
Dhinakaran Veeman ${ }^{1}\left(\mathbb{D}\right.$, Ahmad Alanezi $^{2}$, Hayder Natiq ${ }^{3}\left(\mathbb{D}\right.$, Sajad Jafari $^{4,5}$ and Ahmed A. Abd El-Latif ${ }^{6, *(\mathbb{D})}$ \\ 1 Centre for Additive Manufacturing, Chennai Institute of Technology, Chennai 600069, India; \\ dhinakaranv@citchennai.net \\ 2 Computer Science and Applied Mathematics, Faculty of Engineering and Technology, Liverpool John Moores \\ University, Kingsway House Crosby Rd N, Liverpool L3 2AJ, UK; A.D.Alanezi@2019.ljmu.ac.uk \\ 3 Department of Computer Techniques Engineering, Information Technology College, Imam Ja'afar Al-Sadiq \\ University, Baghdad 10001, Iraq; hayder.natiq@sadiq.edu.iq \\ 4 Department of Biomedical Engineering, Amirkabir University of Technology (Tehran Polytechnic), No. 350, \\ Hafez Ave, Valiasr Square, Tehran 159163-4311, Iran; sajadjafari83@gmail.com \\ 5 Health Technology Research Institute, Amirkabir University of Technology(Tehran Polytechnic), No. 350, \\ Hafez Ave, Valiasr Square, Tehran 159163-4311, Iran \\ 6 Department of Mathematics and Computer Science, Faculty of Science, Menoufia University, \\ Shebeen El-Kom 32511, Egypt \\ * Correspondence: aabdellatif@nu.edu.eg
}

check for updates

Citation: Veeman, D.; Alanezi, A.; Natiq, H.; Jafari, S.; Abd El-Latif, A.A. A Chaotic Quadratic Oscillator with Only Squared Terms: Multistability, Impulsive Control, and Circuit Design. Symmetry 2022, 14, 259 https://doi.org/10.3390/ sym14020259

Academic Editor: Yunlong Shang

Received: 30 October 2021

Accepted: 14 December 2021

Published: 28 January 2022

Publisher's Note: MDPI stays neutral with regard to jurisdictional claims in published maps and institutional affiliations.

Copyright: (C) 2022 by the authors. Licensee MDPI, Basel, Switzerland. This article is an open access article distributed under the terms and conditions of the Creative Commons Attribution (CC BY) license (https:// creativecommons.org/licenses/by/ $4.0 /)$.

\begin{abstract}
Here, a chaotic quadratic oscillator with only squared terms is proposed, which shows various dynamics. The oscillator has eight equilibrium points, and none of them is stable. Various bifurcation diagrams of the oscillator are investigated, and its Lyapunov exponents (LEs) are discussed. The multistability of the oscillator is discussed by plotting bifurcation diagrams with various initiation methods. The basin of attraction of the oscillator is discussed in two planes. Impulsive control is applied to the oscillator to control its chaotic dynamics. Additionally, the circuit is implemented to reveal its feasibility.
\end{abstract}

Keywords: quadratic oscillator; bifurcation; multistability; impulsive control; chaotic circuit

\section{Introduction}

Chaotic flows have attracted lots of attention recently [1,2]. Many systems with various features have been proposed to study the chaotic dynamics [3,4]. Some of the proposed oscillators are discussed from the viewpoint of their quadratic or cubic terms $[5,6]$. Some other studies have focused on the equilibrium points [7]. Oscillators with no equilibria [8], with stable equilibria [9], with curves of equilibria [10], and with a peanut-shaped equilibrium curve [11] are some examples. A hyperjerk oscillator has been investigated in [12] A multi-dimensional chaotic system was discussed in [13]. In [14], a multi-scroll chaotic circuit was analyzed. Various dynamics of the Sprott B system were studied in [15]. The dynamics of coupled neurons were investigated in [16]. Chaotic dynamics have many applications, such as encryption [17-19]. In [20,21], a discrete chaotic dynamic was used in image encryption. A chaotic encryption method and its application in the internet of things were studied in [22]. A plain-text-related image encryption method using Chen oscillator was proposed in [23].

Multistability is an exciting feature of dynamical systems [24-26]. Multistable oscillators have various applications [27]. A multistable oscillator with various attractors was discussed in [28]. In [29,30], the multistability of the series hybrid electric vehicle was investigated. Extreme multistability is a particular case of multistability [31]. In [32], the extreme multistability of a fractional-order oscillator was studied. The multistability of a Chua system was discussed in [33]. Memristive chaotic oscillators are very interesting [34]. 
A memristive neural system was studied in [35]. A memristive Chua system was discussed in [36]. In [37], a memristive oscillator with a unique attractor was investigated. A memristive oscillator with a fractional-order difference was studied in [38]. In [39], the multistability of a five-value memristive oscillator was investigated.

Control and synchronization of dynamical systems have been a hot topic [40-42]. Many algorithms have been proposed to control chaotic oscillators [43]. Control of the Chen oscillator was investigated in [44]. A fuzzy-based controller was studied in [45]. In [46], control of a piecewise linear oscillator was discussed. Adaptive control of a chaotic oscillator was discussed in [47]. Delayed feedback control of chaotic oscillators was investigated in [48]. Impulsive control is a valuable method for this purpose [49]. Event-triggered impulsive control was studied in [50-52]. Synchronization of the Chen oscillator was discussed in [53]. Impulsive control for synchronization of a chaotic network was investigated in [54].

Chaotic circuits show the feasibility of these dynamics [55,56]. Implementing circuits for chaotic oscillators has been an exciting topic [57]. A memristive circuit was studied in [1]. Various dynamics of the system were discussed. A jerk circuit with the arcsinh function was proposed in [58], and its behaviors were investigated. The application of a chaotic circuit on image encryption was discussed in [59]. The circuit design of a 5D hyperchaotic oscillator was studied in [60], and its multistability was discussed. In [61], the circuit design of a 3D system was studied.

Here, a quadratic oscillator with only squared terms is presented. The comparison of the proposed system with some previous important literature is presented in Table 1 to highlight the distribution of this paper. The proposed system is a simple quadratic system with only squared terms, and some important properties of the system are investigated. The chaotic behavior of the oscillator is discussed in Section 2. Additionally, its equilibrium points and their stabilities are investigated. In Section 3, various oscillator dynamics are discussed by changing its three parameters. 1D and 2D bifurcation diagrams are used to investigate the dynamics of the oscillator. Lyapunov exponents (LEs) help to investigate the type of dynamics in various parameters. Then by plotting bifurcation diagrams with various initial conditions, the multistability of the oscillator is investigated. The basin of attraction for the oscillator shows the variation of dynamics by changing the initial values of its three variables. In Section 4, the impulsive control of the oscillator is designed, and its results are discussed. Then, the circuit of the oscillator is designed in Section 5. In Section 6, the conclusion of the paper is discussed.

Table 1. Comparison of the proposed system with the previous ones.

\begin{tabular}{ccccccc}
\hline Ref. & Dimension & Type of Terms & $\begin{array}{c}\text { Number of } \\
\text { Terms }\end{array}$ & $\begin{array}{c}\text { Number of } \\
\text { Equilibrium } \\
\text { Points }\end{array}$ & Multistability & Circuit \\
\hline$[62]$ & 4 & Cubic & 9 & Infinite & $\checkmark$ & $\checkmark$ \\
{$[63]$} & 3 & Cubic \& tanh(.) & 7 & 5 & $\checkmark$ & $\checkmark$ \\
{$[64]$} & 4 & Quadratic & 9 & $3-7$ & $\checkmark$ & $\checkmark$ \\
{$[16]$} & 3 & Linear \& Tanh & 10 & 8 & $\checkmark$ \\
This work & 3 & Quadratic with only & 9 & & $\checkmark$ \\
\hline
\end{tabular}

\section{The Proposed Oscillator}

A quadratic oscillator is presented as:

$$
\begin{gathered}
\dot{x}=-y^{2}+z^{2}+C_{2} x^{2}+C_{1} \\
\dot{y}=-z^{2}+x^{2}+2 \\
\dot{z}=z^{2}+C_{3} x^{2}
\end{gathered}
$$


To propose the system, a parametric quadratic system with only squared terms and constants in each variable is designed. Then a computer search is applied to compute the value of parameters and initial values for chaotic solutions. The oscillator only has squared terms and not a multiplication of two variables. It is important to investigate if this system is symmetric or has offset boosting properties. Offset boosting and symmetry experiments are significant features of chaotic systems $[65,66]$. We examine the existence of offset boosting and symmetry by adding a constant excitation force to all the right-hand sides of equations one by one. However, there was no offset boosting. The system shows chaotic dynamics in $C_{1}=-0.6, C_{2}=-0.7, C_{3}=-2$ and initial conditions $(0,0,0)$. Figure 1 presents the time series of chaotic dynamics in part (a), the 3D chaotic attractor in part (b), and its three $2 \mathrm{D}$ projections in $X-Y, Y-Z$, and $X-Z$ planes with gray color.
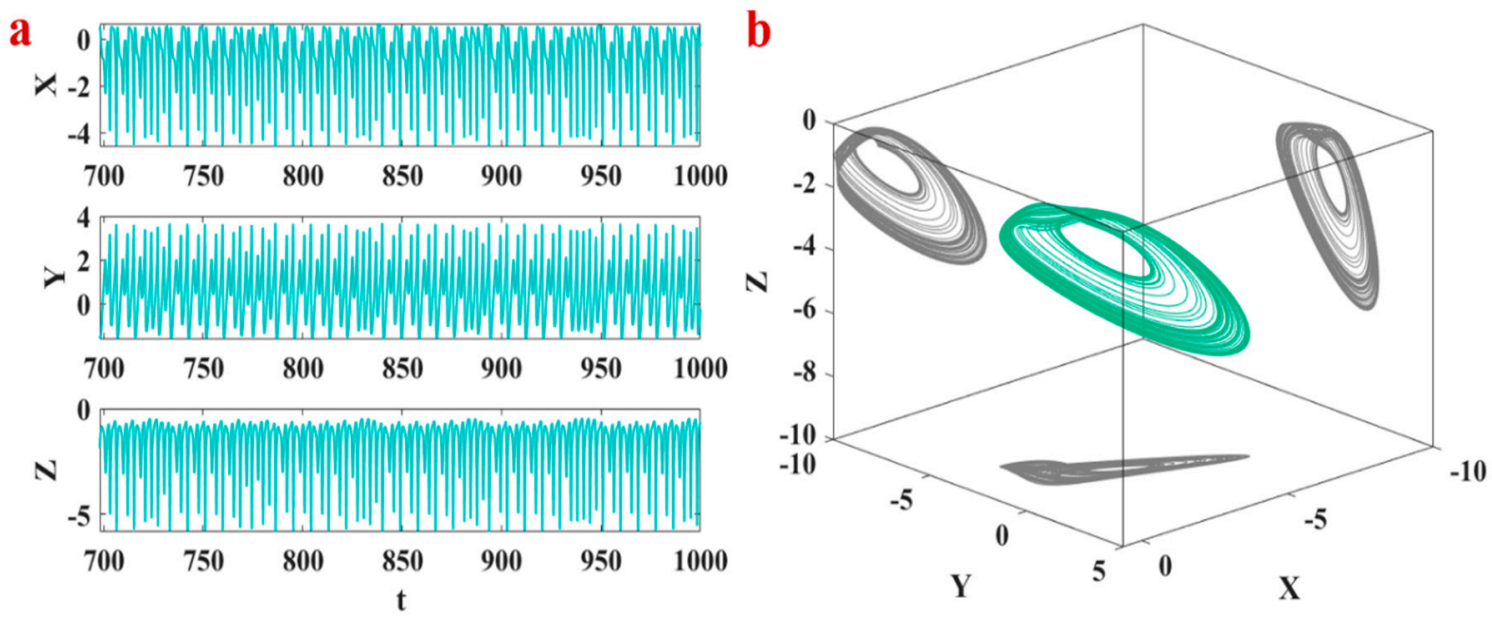

Figure 1. Chaotic dynamics of the presented oscillator in $C_{1}=-0.6, C_{2}=-0.7, C_{3}=-2$ and initial conditions $(0,0,0) ;(\mathbf{a})$ time series; (b) phase space.

The equilibrium points of the system are calculated by setting zeros on the right-hand side of Equation (1). The system has eight equilibrium points, as shown in Table 1. To investigate the stability of equilibrium points, the characteristic equation and eigenvalues should be computed for each of them. The corresponding eigenvalues of the equilibrium points are presented in Table 2. All of the equilibrium points have at least one positive real part of the eigenvalue, so they are unstable.

Table 2. Equilibrium points and eigenvalues of Oscillator (1).

\begin{tabular}{ccc}
\hline$\#$ & Equilibrium & Eigenvalues \\
\hline$E_{1}$ & $(\sqrt{2}, \sqrt{2}, 2)$ & $\lambda_{1}=-1.2036, \lambda_{2,3}=1.6118 \pm 4.8979 i$ \\
$E_{2}$ & $(-\sqrt{2}, \sqrt{2}, 2)$ & $\lambda_{1}=8.9257, \lambda_{2,3}=-1.4729 \pm 1.1899 i$ \\
$E_{3}$ & $(\sqrt{2},-\sqrt{2}, 2)$ & $\lambda_{1}=3.1356, \lambda_{2,3}=-0.5577 \pm 3.1455 i$ \\
$E_{4}$ & $(-\sqrt{2},-\sqrt{2}, 2)$ & $\lambda_{1}=6.2323, \lambda_{2}=-2.3957, \lambda_{3}=2.1432$ \\
$E_{5}$ & $(\sqrt{2}, \sqrt{2},-2)$ & $\lambda_{1}=-6.2323, \lambda_{2}=2.3957, \lambda_{3}=-2.1432$ \\
$E_{6}$ & $(-\sqrt{2}, \sqrt{2},-2)$ & $\lambda_{1}=-3.1356, \lambda_{2,3}=0.5577 \pm 3.1455 i$ \\
$E_{7}$ & $(\sqrt{2},-\sqrt{2},-2)$ & $\lambda_{1}=-8.9257, \lambda_{2,3}=1.4729 \pm 1.1899 i$ \\
$E_{8}$ & $(-\sqrt{2},-\sqrt{2},-2)$ & $\lambda_{1}=1.2036, \lambda_{2,3}=-1.6118 \pm 4.8979 i$ \\
\hline
\end{tabular}

\section{Dynamical Properties}

The oscillator has three crucial parameters that significantly affect its dynamics. The first studied parameter is $C_{1}$. Figure 2 presents the bifurcation diagram of Oscillator (1) by 
varying $C_{1}$. The other parameters are kept constant as $C_{2}=-0.7, C_{3}=-2$. The maximum values of three variables of the oscillator with the forward continuation method are plotted in parts $(\mathrm{a}-\mathrm{c})$. The oscillator shows a period-doubling route to chaos. Part (d) of the Figure $2 \mathrm{~d}$ shows the oscillator's LEs by changing $C_{1}$. A positive LE can prove the existence of chaos. Additionally, one LE approaches zero by approaching bifurcation points.
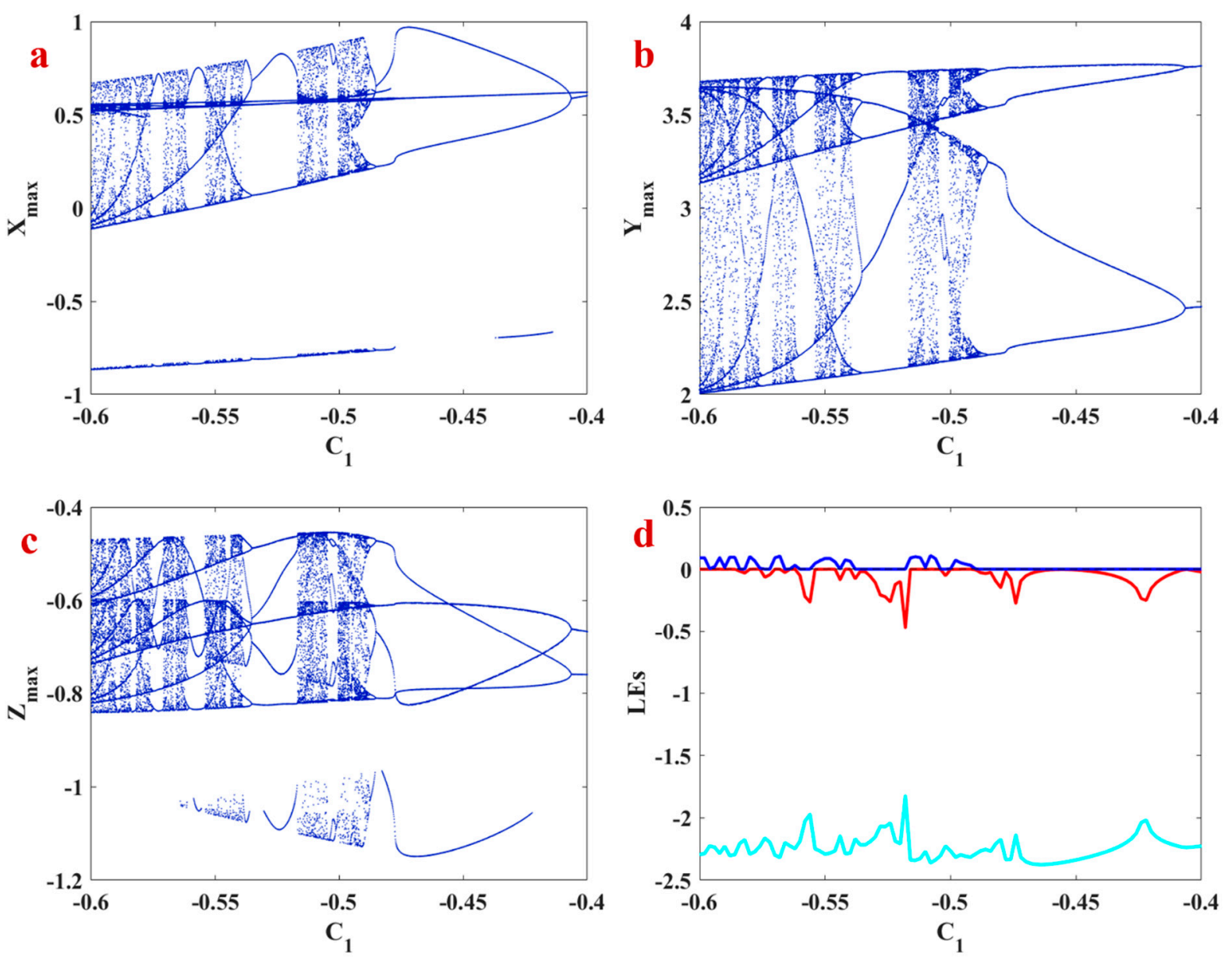

Figure 2. Bifurcation diagram by varying $C_{1}$ with forwarding continuation method; The first initial conditions are $(0,0,0)$; (a) peak values of $x$ variable; (b) peak values of $y$ variable; (c) peak values of $z$ variable; (d) LEs.

The bifurcation diagram is discussed by changing $C_{2}$ in Figure 3 . The diagram is plotted using a forward continuation method in constant parameters $C_{1}=-0.6, C_{3}=-2$. A period-doubling route to chaos can be seen by changing the parameter. LEs of the oscillator confirm the chaotic dynamics in small $C_{2}$.

To better investigate various dynamics of the oscillator, the 2D bifurcation diagrams are discussed by changing parameters $C_{1}$ and $C_{2}$ in Figure 4 . A classic bifurcation diagram presents the dynamics by changing one parameter. The $2 \mathrm{D}$ bifurcation diagram is helpful since it shows the variations by changing two parameters. The bifurcation diagram by changing $C_{1}$ is plotted for nine values of parameter $C_{2}$. The diagram helps to investigate various dynamics by changing these two parameters. The results show that in the studied interval of $C_{1}$, increasing $C_{2}$ causes a decrease in the complexity of dynamics. 

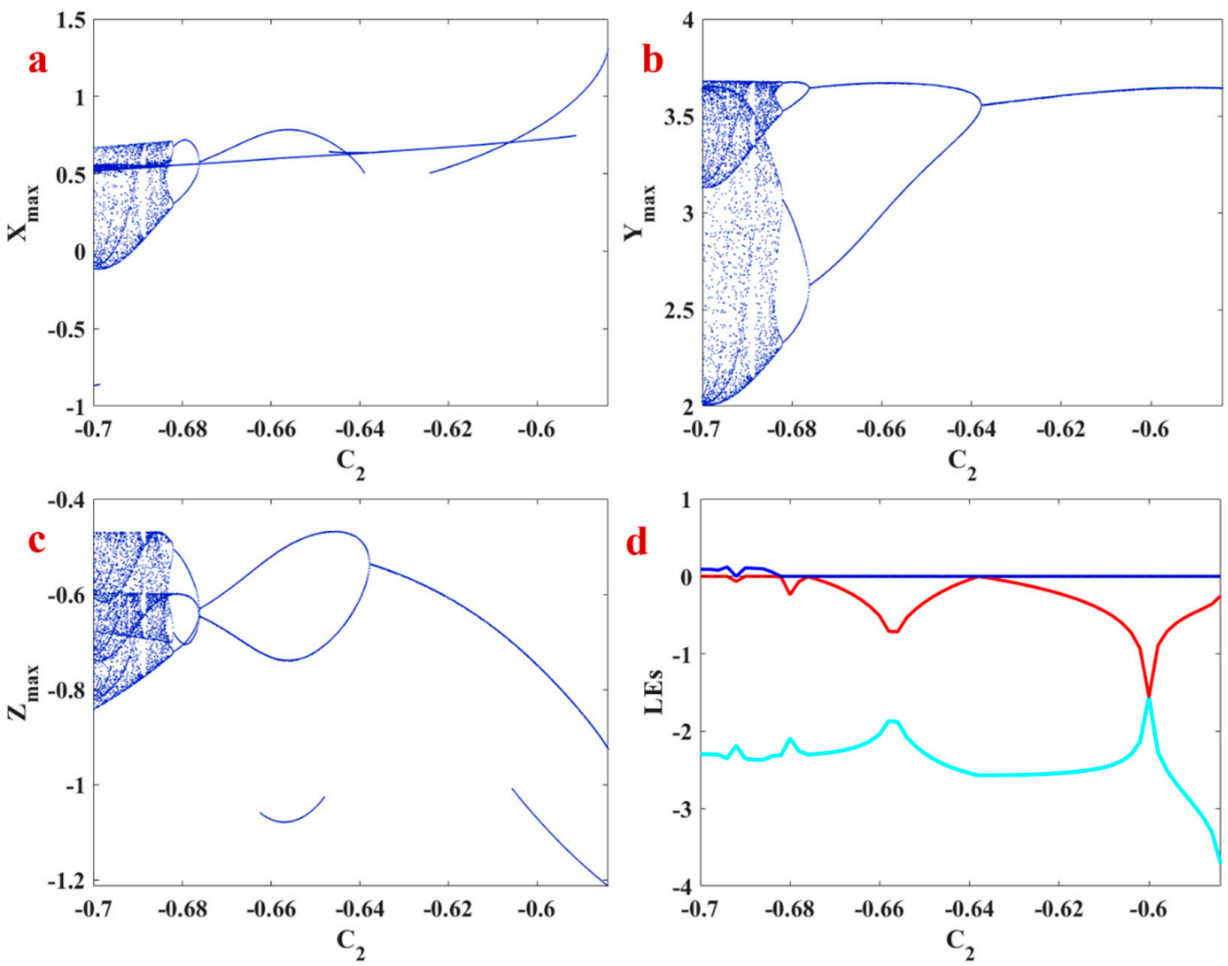

Figure 3. Bifurcation diagram by varying $C_{2}$ with forwarding continuation method; The first initial conditions are $(0,0,0)$; (a) peak values of $x$ variable; (b) peak values of $y$ variable; (c) peak values of $z$ variable; (d) LEs.
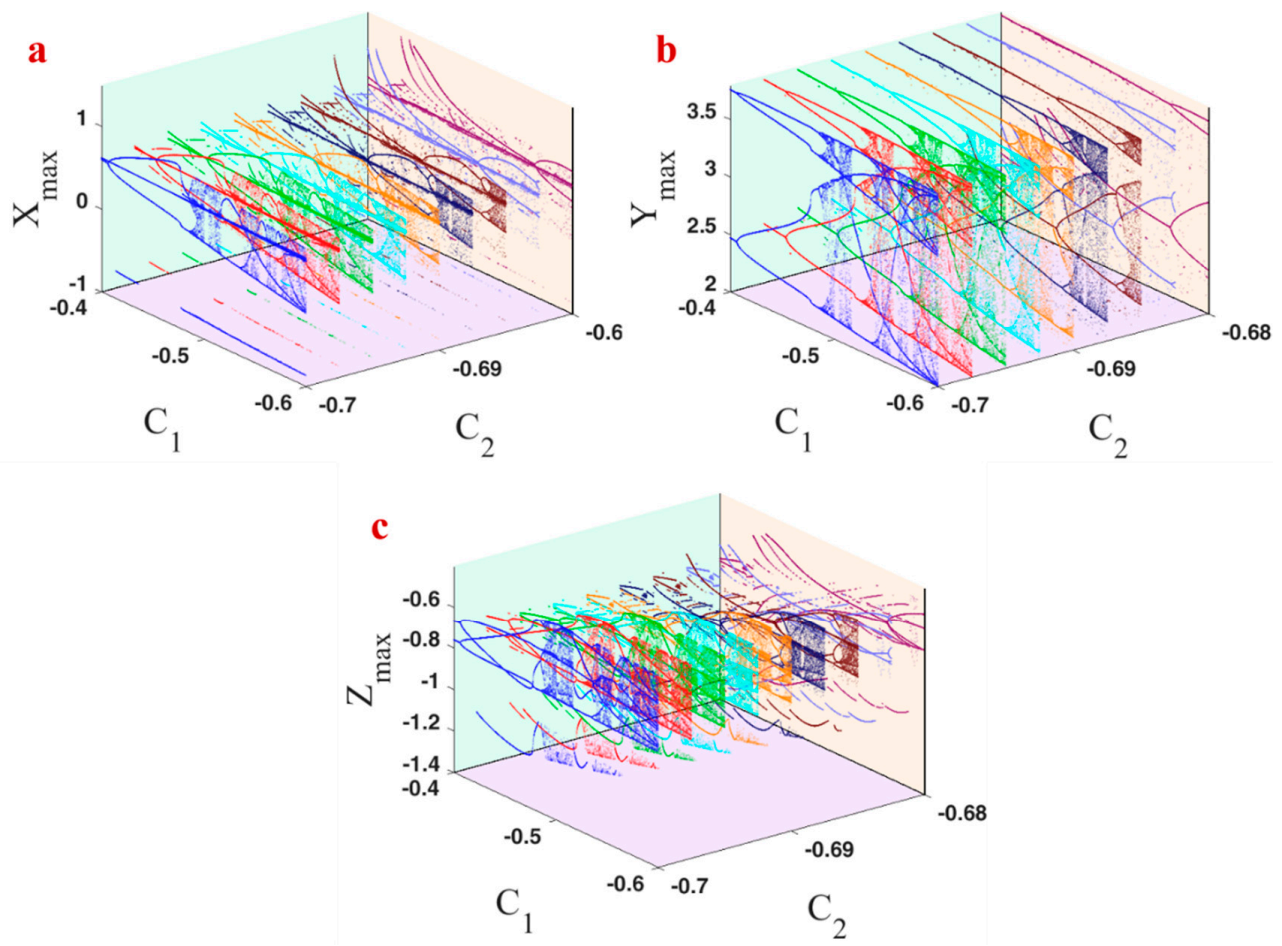

Figure 4. Bifurcation diagram of the oscillator by changing parameters $C_{1}$ and $C_{2}$; the diagrams are plotted by constant initial values at origin; (a) maximum values of $x$; (b) maximum values of $y$; (c) maximum values of $z$. 
The multistability of the oscillator can be revealed by plotting a bifurcation diagram with different initial conditions. In Figure 5, various bifurcations are plotted using different colors in parameters $C_{1}=-0.6$ and $C_{2}=-0.7$. The magenta color shows a bifurcation diagram in $C_{3} \in[-2,-1.953]$. It is plotted by the forward continuation method and the first initial conditions at the origin. The blue one is the forward continuation bifurcation diagram with origin as the first initial conditions. The green color is the forward bifurcation in $C_{3} \in[-1.9836,-1.983]$ and the first initial conditions as $(0,0,0)$. Comparison of the magenta color diagram with blue and green ones reveals the coexisting attractors in various intervals of $C_{3}$.
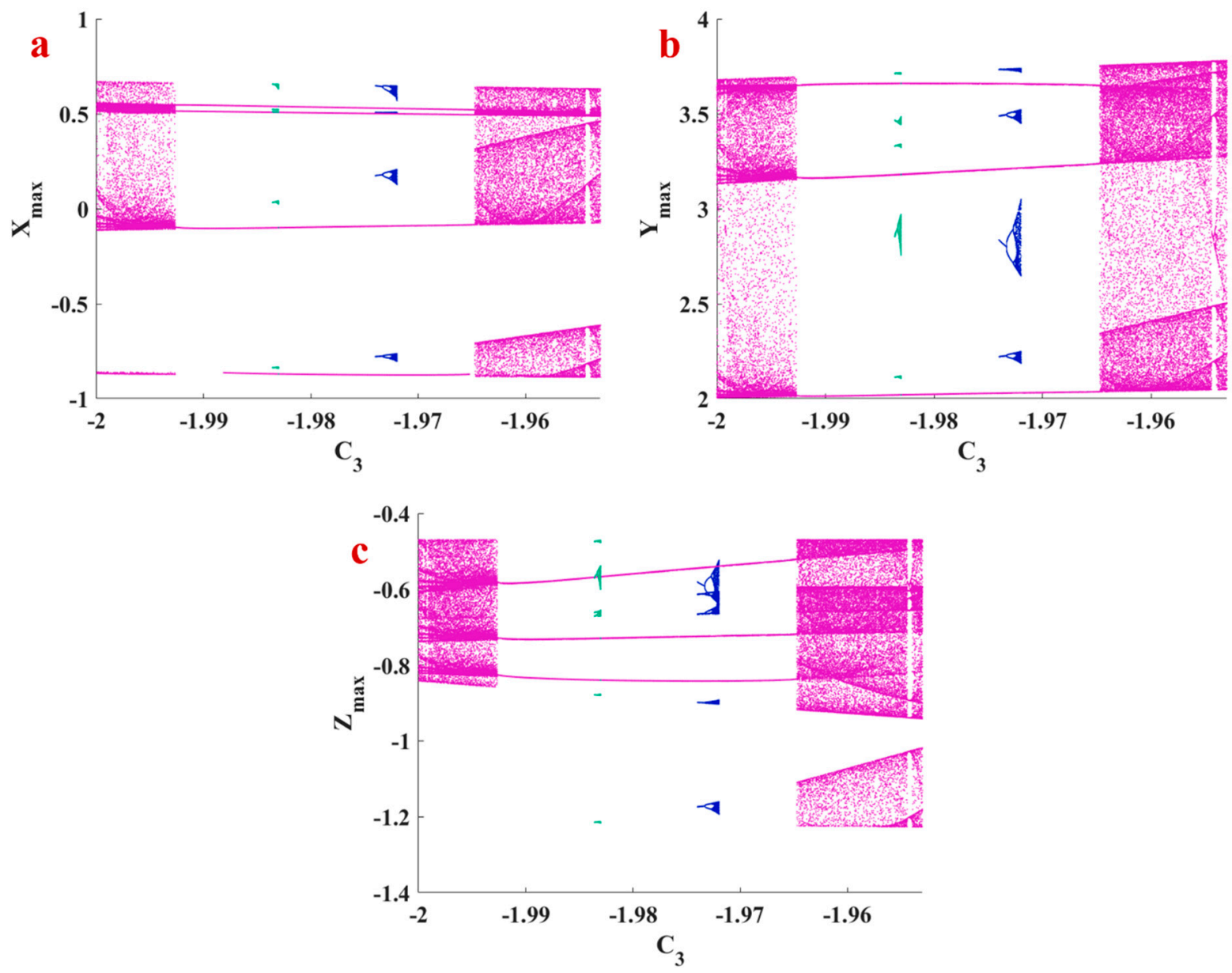

Figure 5. Forward bifurcation diagram with origin as the first initial conditions; the blue diagram in $C_{3} \in[-1.974,-1.965]$, the magenta diagram in the interval $C_{3} \in[-2,-1.953]$, and the green diagram in $C_{3} \in[-1.9836,-1.983]$; (a) peak values of $x$ variable; (b) peak values of $y$ variable; (c) peak values of $z$ variable;

The basin of attraction of the oscillator in $C_{1}=-0.6, C_{2}=-0.7, C_{3}=-1.9722$ is discussed to investigate the initial conditions that result in chaotic and periodic dynamics as presented in Figure 5. In Figure 6, the basin of attractions is plotted in two planes as $z_{0}=0$ and $z_{0}=1$. The pink color shows chaotic regions, and the white one presents the periodic regions. The gray color depicts unbounded regions. In each plane, the dynamics in the intervals $x_{0} \in[-3,7], y_{0} \in[-4,4]$ are computed for constant $z_{0}$. So the variations of dynamics by changing $x_{0}$ and $y_{0}$ can be seen in each plane. The effect of $z_{0}$ can be seen by comparing the two planes. Four sets of initial conditions are selected from the two planes to show the coexisting chaotic and periodic attractors (Figure 7). 


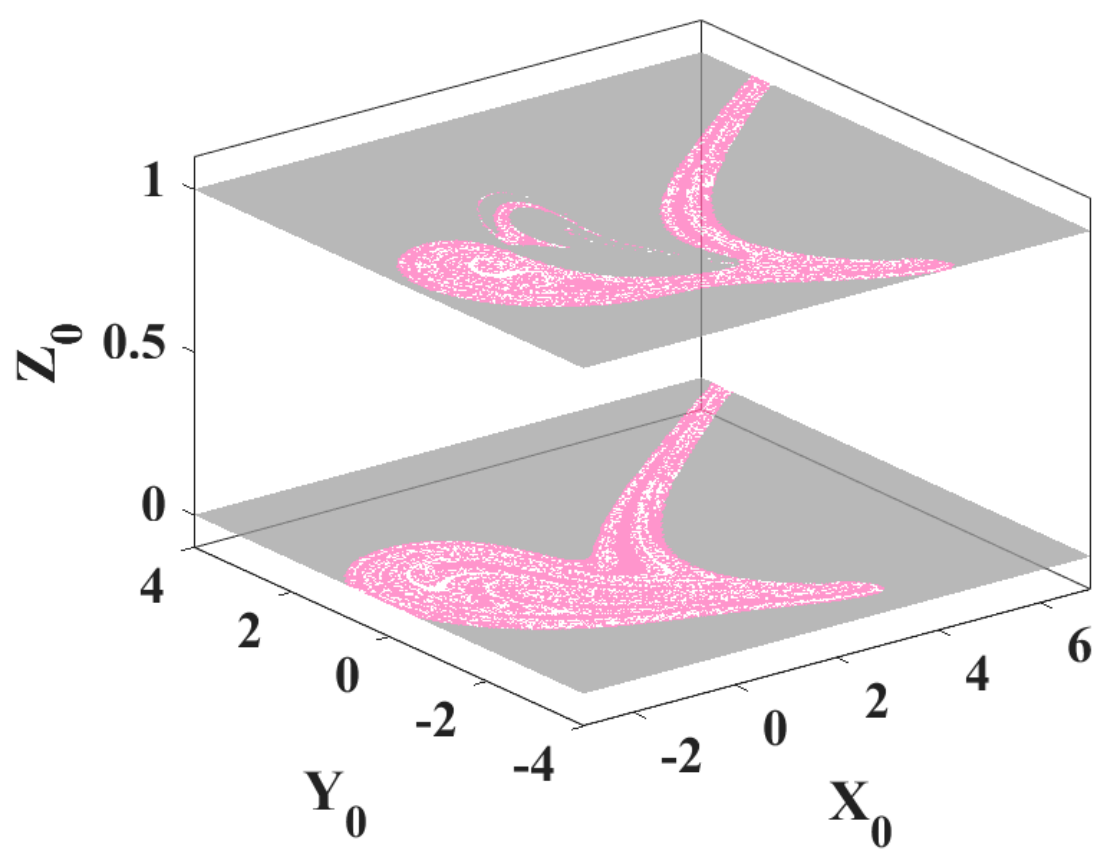

Figure 6. Basin of attraction in $C_{1}=-0.6, C_{2}=-0.7, C_{3}=-1.9722$; pink color shows the chaotic region, white shows the periodic region, and gray color presents unbounded regions; two planes are computed for two $z_{0}$.
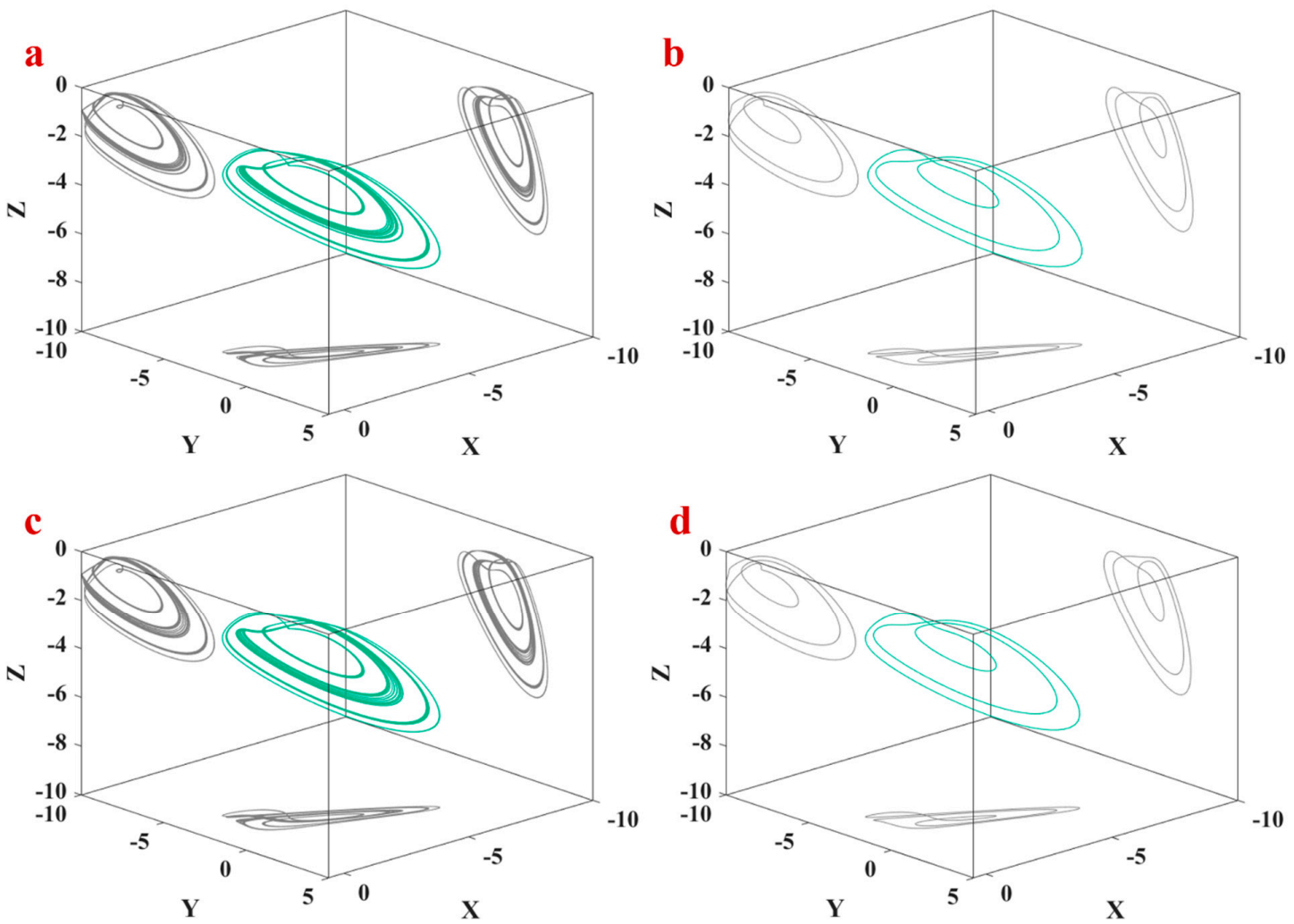

Figure 7. Attractors of the oscillator in $C_{1}=-0.6, C_{2}=-0.7, C_{3}=-1.9722$ and (a) $\left(x_{0}, y_{0}, z_{0}\right)=$ $(-0.05,-1.4,0) ; \quad$ (b) $\left(x_{0}, y_{0}, z_{0}\right)=(-0.05,-1.44,0) ; \quad$ (c) $\left(x_{0}, y_{0}, z_{0}\right)=(-0.05,-2.14,1)$; (d) $\left(x_{0}, y_{0}, z_{0}\right)=(-0.05,-2.12,1)$; the $2 \mathrm{D}$ projections of the attractors are plotted in gray color. 


\section{Impulsive Control}

In this section, impulsive control $[67,68]$ is applied to stabilize the proposed oscillator. As was discussed in Table 2, the system does not have an equilibrium point in origin. So in the first step, the change of variables $x_{\text {new }}=x_{\text {old }}-\sqrt{2}, y_{\text {new }}=y_{\text {old }}-\sqrt{2}, z_{\text {new }}=z_{\text {old }}-2$ is used to move the equilibrium point $\left(x^{*}, y^{*}, z^{*}\right)=(\sqrt{2}, \sqrt{2}, 2)$ to the origin. So the transformed oscillator is as follows:

$$
\begin{gathered}
\dot{x}=-\left(y+y^{*}\right)^{2}+\left(z+z^{*}\right)^{2}-0.7\left(x+x^{*}\right)^{2}-0.6 \\
\dot{y}=-\left(z+z^{*}\right)^{2}+\left(x+x^{*}\right)^{2}+2 \\
\dot{z}=\left(z+z^{*}\right)^{2}-2\left(x+x^{*}\right)^{2}
\end{gathered}
$$

where $x_{\text {new }}, y_{\text {new }}, z_{\text {new }}$ are called $x, y, z$ in Equation (2). Then Oscillator (2) can be rewritten as:

$$
\dot{P}=A \times P+\phi(P)
$$

where $P$ is the vector of variables $[x, y, z]^{T}, A \times P$ is the linear term of Equation (2), and $\phi(P)$ is the nonlinear term. From Equation (2), we have:

$$
A=\left[\begin{array}{ccc}
-1.4 \times x^{*} & -2 \times y^{*} & 2 \times z^{*} \\
2 \times x^{*} & 0 & -2 \times z^{*} \\
-4 \times x^{*} & 0 & 2 \times z^{*}
\end{array}\right], \quad \phi(P)=\left[\begin{array}{c}
-y^{2}+z^{2}-0.7 x^{2} \\
-z^{2}+x^{2} \\
z^{2}-2 x^{2}
\end{array}\right]
$$

Now the controlled oscillator can be written as:

$$
\begin{aligned}
& \dot{P}=\mathrm{g}(t, P)=A \times P+\phi(P) \quad t \neq \tau_{i} \\
& P\left(t^{+}\right)-P\left(t^{-}\right)=B \times P \quad t=\tau_{i}, i=1,2, \ldots
\end{aligned}
$$

So $B, \tau_{i}$ should be calculated for this control method.

Definition 1. If $V V: R_{+} \times R^{n} \rightarrow R_{+}$, then $V V$ belong to the class $V V_{0}$, if:

(1) $V V$ is continuous in $\left(\tau_{i-1}, \tau_{i}\right] \times R^{n}$ and for each $P \in R^{n}, \mathrm{i}=1,2, \ldots,(t, Y) \rightarrow\left(\tau_{i}^{+}, P\right)$ $\lim V V(t, Y)=V V\left(\tau_{i}^{+}, P\right)$ exists;

(2) $V V$ is locally Lipschitzian in $P$.

Definition 2. For $(t, P) \in\left(\tau_{i-1}, \tau_{i}\right] \times R^{n}$, we have,

$$
D^{+} V V(t, P) \triangleq h \rightarrow 0+\lim \sup \frac{1}{h}[V V(t+h, P+h g(t, P)-V V(t, P)]
$$

Definition 3. Comparison system: $V V \in V V 0$ and consider:

$$
D^{+} V V(t, X) \leq a(t, V V(t, P)), t \neq \tau_{i} ; \text { and } V V(t, P+U U(i, P)) \leq \Psi i(V V(t, P)), t=\tau_{i},
$$

where $a: R_{+} \times R_{+} \rightarrow R$ is continuous and $\Psi i: R_{+} \rightarrow R_{+}$is non-decreasing. Then the following system is the comparison system:

$$
\begin{aligned}
& \omega \omega=a(t, \omega), t \neq \tau_{i} \\
& \omega \omega\left(\tau_{i}^{+}\right)=\Psi i\left(\omega \omega\left(\tau_{i}\right)\right) \\
& \omega \omega\left(\tau_{0}^{+}\right)=\omega \omega 0 \geq 0
\end{aligned}
$$

Theorem 1. The following conditions are considered:

(1) $V V: R^{n} \times R^{n} \rightarrow R_{+}, V V \in V V 0, K K(t) D^{+} V V(t, P)+D^{+} K K(t) V V(t, P) \leq$ $a(t, K K(t) V V(t, P)), t \triangleq l i$, when $a$ is continuous in $\left(\tau_{i-1}, \tau_{i}\right] \times R^{n}$ for each $P \in R^{n}$, $i=1,2, \ldots,(t, y) \rightarrow\left(\tau_{i}^{+}, P\right) \lim a(t, y)=a\left(\tau_{i}^{+}, P\right)$ exists. $K K(t) \geq m m>0, t \rightarrow$ 
$\tau_{i}^{+} \lim K K(t)=K K\left(\tau_{i}\right), t \rightarrow \tau_{i}^{+} \lim K K(t)$ exists, $i=1,2, \ldots, D^{+} K K(t)=h \rightarrow 0+$ $\limsup \left(\frac{1}{h}\right)[K K(t+h)-K K(t)]$;

(2) $K K\left(\tau_{i}+0\right) V V\left(\tau_{i}+0, P+U U(k k, P)\right) \leq \Psi i\left(K K\left(\tau_{i}\right) V V\left(\tau_{i}, P\right)\right), i=1,2, \ldots$;

(3) $V V(t, 0)=0$ and $\alpha(\|P\|) \leq V V(t, P)$ on $R_{+} \times R^{n}$, when $\alpha(\cdot) \in \aleph$ (continuous strictly increasing function class $\alpha: R_{+} \rightarrow R_{+}$so that $\alpha(0)=0$ ) are satisfied. The global asymptotic stability for the solution $\omega \omega=0$ of the comparison system implies global asymptotic stability of impulsive system trivial solution.

Theorem 2. Consider $a(t, \omega \omega)=\dot{\lambda}(t) \omega \omega, \Psi i(\omega \omega)=d_{i} \omega \omega, d_{i} \geq 0$ for all $i \geq 1$. Consequently, the system origin is global asymptotically stable if Theorem 1 conditions and the following conditions are kept:

(1) $\lambda(t)$ is non-decreasing, $t \rightarrow \tau_{i}^{+} \lim \lambda(t)=\lambda\left(\tau_{i}\right), t \rightarrow \tau_{i}^{+} \lim \lambda(t)=\lambda\left(\tau_{i}^{+}\right)$exists, for all $=1,2, \ldots$;

(2) $\sup _{i}\left[d_{i} \exp \left(\lambda\left(\tau_{i+1}\right)-\lambda\left(\tau_{i}^{+}\right)\right)\right]=\varepsilon \varepsilon_{0}<\infty$;

(3) There is a $r>1$ such that $\lambda\left(\tau_{2 i+3}\right)+\lambda\left(\tau_{2 i+2}\right)+\ln \left(r d_{2 i+2}+d_{2 i+1}\right) \leq \lambda\left(\tau_{2 i+2}{ }^{+}\right)+$ $\lambda\left(\tau_{2 i+2}{ }^{+}\right)$is held for all $d_{2 i+2} d_{2 i+1} \neq 0, i=1,2, \ldots$, or there is a $r>1$ so that $\lambda\left(\tau_{i+1}\right)+$ $\ln \left(r d_{i}\right) \leq \lambda\left(\tau_{i}^{+}\right)$for all $i$;

(4) $V V(t, 0)=0$, and we have $\alpha(\cdot)$ in class $N$ such that $\alpha(\|P\|) \leq V V(t, P)$.

Theorem 3. The origin is an asymptotically stable equilibrium for the proposed oscillator if there is $a \xi>1$ and a differentiable at $t \neq \tau_{i}$ and non-increasing function $K K(t)$ which satisfies:

$$
\begin{gathered}
-\frac{K \dot{K}(t)}{K K(t)} \leq q+r \leq \frac{1}{(1+\varepsilon \varepsilon) \Delta_{2}} \ln \left(\frac{K K\left(\tau_{2 i}^{+}\right) K K\left(\tau_{2 i-1}^{+}\right)}{K K\left(\tau_{2 i+1}\right) K K\left(\tau_{2 i}\right) \zeta^{2} d^{2}}\right) \\
-\frac{K \dot{K}(t)}{K K(t)} \leq q+r \leq \frac{1}{\max \left(\Delta_{1}, \Delta_{2}\right)} \ln \left(\frac{K K\left(\tau_{i}^{+}\right)}{K K\left(\tau_{i+1}\right) \xi^{j} d}\right) \\
r=\left\{\begin{array}{cc}
0, & \text { if } K=I \\
2 M \sqrt{\frac{\lambda_{2}}{\lambda_{1}}} & \text { if } K \neq I
\end{array}\right.
\end{gathered}
$$

where $q$ is defined as the largest eigenvalue of $\left(A+K^{-1} A^{T} K\right), K$ is a positive definite matrix, and $\lambda_{1}>0$ and $\lambda_{2}>0$ are the smallest and the largest eigenvalues of $K$, respectively. $\rho(V)$ is the spectral radius of $V$ and $d=\rho^{2}(I+B)$. M is considered as $\left|x_{(t)}\right|<M,\left|y_{(t)}\right|<M,\left|z_{(t)}\right|<M$. $K K(t)$ is as in Theorem $1, \tau_{i}: i=1,2, \ldots$ should satisfy:

$$
\begin{aligned}
& \Delta_{1}=\sup _{1 \leq i<\infty}\left(T_{2 i+1}-T_{2 i}\right)<\infty \\
& \Delta_{2}=\sup _{1 \leq i<\infty}\left(T_{2 i}-T_{2 i-1}\right)<\infty
\end{aligned}
$$

For a constant $\varepsilon$, we have:

$$
T_{2 i+1}-T_{2 i} \leq \varepsilon\left(T_{2 i}-T_{2 i-1}\right), \forall i \in 1,2, \ldots, \infty
$$

The theorem's proof can be seen in [67].

Remark 1. Theorem 3 estimates the upper bound $\Delta_{1 \max }$ and $\Delta_{2 \max }$ of impulsive intervals.

$$
\begin{gathered}
\Delta_{1}=\frac{1}{(1+\varepsilon \varepsilon)(q+2|a \alpha|)} \ln \left(\frac{K K\left(\tau_{2 i}^{+}\right) K K\left(\tau_{2 i-1}^{+}\right)}{K K\left(\tau_{2 i+1}\right) K K\left(\tau_{2 i}\right) \zeta^{2} d^{2}}\right) \\
\Delta_{2}=\varepsilon \varepsilon \Delta_{1}
\end{gathered}
$$


For controlling the proposed oscillator, the matrix $B$ is considered as:

$$
B=\left[\begin{array}{ccc}
-1.1 & 0 & 0 \\
0 & -1 & 0 \\
0 & 0 & -1
\end{array}\right]
$$

Here, $q$ is defined as the largest eigenvalue of $\left(A+K^{-1} A^{T} K\right)$, where $K$ is a positive definite matrix. By considering $K=I, q$ is calculated as the maximum eigenvalue of $\left(A+A^{T}\right)$. For the Oscillator (2), $q=9.8272$.

Another parameter in this control method is $d$ which is defined as:

$$
d=\rho^{2}(I+B)
$$

where $\rho(V)$ is the spectral radius of $V$. So, we have $d=(-1.1+1)^{2}=0.01$. Then the intervals of applying the controller are computed as:

$$
\begin{gathered}
T_{2 j+1}-T_{2 j}=T_{2 j}-T_{2 j-1}=\Delta<\left(\Delta_{1}=\Delta_{2}\right) \\
\Delta_{1}=\Delta_{2}=\frac{-\ln (\xi) d)}{q}
\end{gathered}
$$

where $\xi$ is considered 1.1; we have $\Delta_{1}=0.4589$. So $\Delta$ is considered 0.45 . Figure 8 presents the results of applying the discussed controller. Part (a) of the figure shows the controlled system (2), while in part (b), the original time series of the oscillator for various variables are plotted in the same time interval. So the controller makes all variables approach zero.
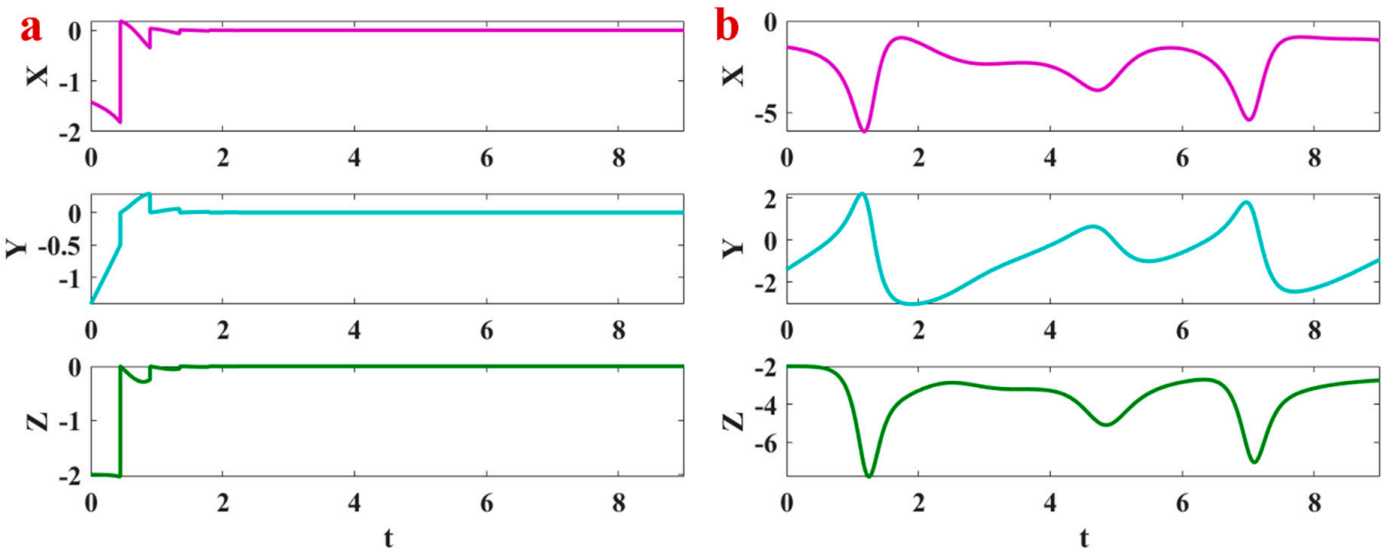

Figure 8. Time series of (a) controlled system (b) original system for various variables by initial conditions $(-\sqrt{2},-\sqrt{2},-2)$.

\section{Circuit Design}

Here the circuit of the oscillator is investigated in $C_{1}=-0.6, C_{2}=-0.7, C_{3}=-2$, as its schematic is shown in Figure 9. The circuit is implemented with OrCAD-Pspice. The values of resistors are considered as $\operatorname{Res}_{1}=\operatorname{Res}_{2}=\operatorname{Res}_{5}=\operatorname{Res}_{6}=\operatorname{Res}_{8}=70 \mathrm{k} \Omega, \operatorname{Res}_{3}=$ $100 \mathrm{k} \Omega, \operatorname{Res}_{4}=17500 \mathrm{k} \Omega, \operatorname{Res}_{7}=5250 \mathrm{k} \Omega, \operatorname{Res}_{9}=35 \mathrm{k} \Omega, \operatorname{Res}_{10}=\operatorname{Res}_{11}=\operatorname{Res}_{12}=$ $\operatorname{Res}_{13}=\operatorname{Res}_{14}=\operatorname{Res}_{15}=100 \mathrm{k} \Omega$. The capacitors are selected as $\operatorname{Cap}_{1}=\operatorname{Cap}_{2}=\mathrm{Cap}_{3}=$ $10 \mathrm{nF}$. Here, AD633 was used as a multiplier, and OPA404 was used as the operational amplifier. The positive voltage source is set to $15 \mathrm{~V}$. The initial values of voltage in capacitors are considered as $(0,0,0)$. Figure 10 presents the results of the designed circuit for the Oscillator (1). Part (a) of the figure shows the time series of the chaotic circuit, while the other parts show the projection of its dynamics in three different planes. The results are wholly matched with the dynamics of Figure 1. In other words, the chaotic oscillator was completely implemented without any issue, and its feasibility was realized. So the oscillator with only squared terms is physically realizable. 

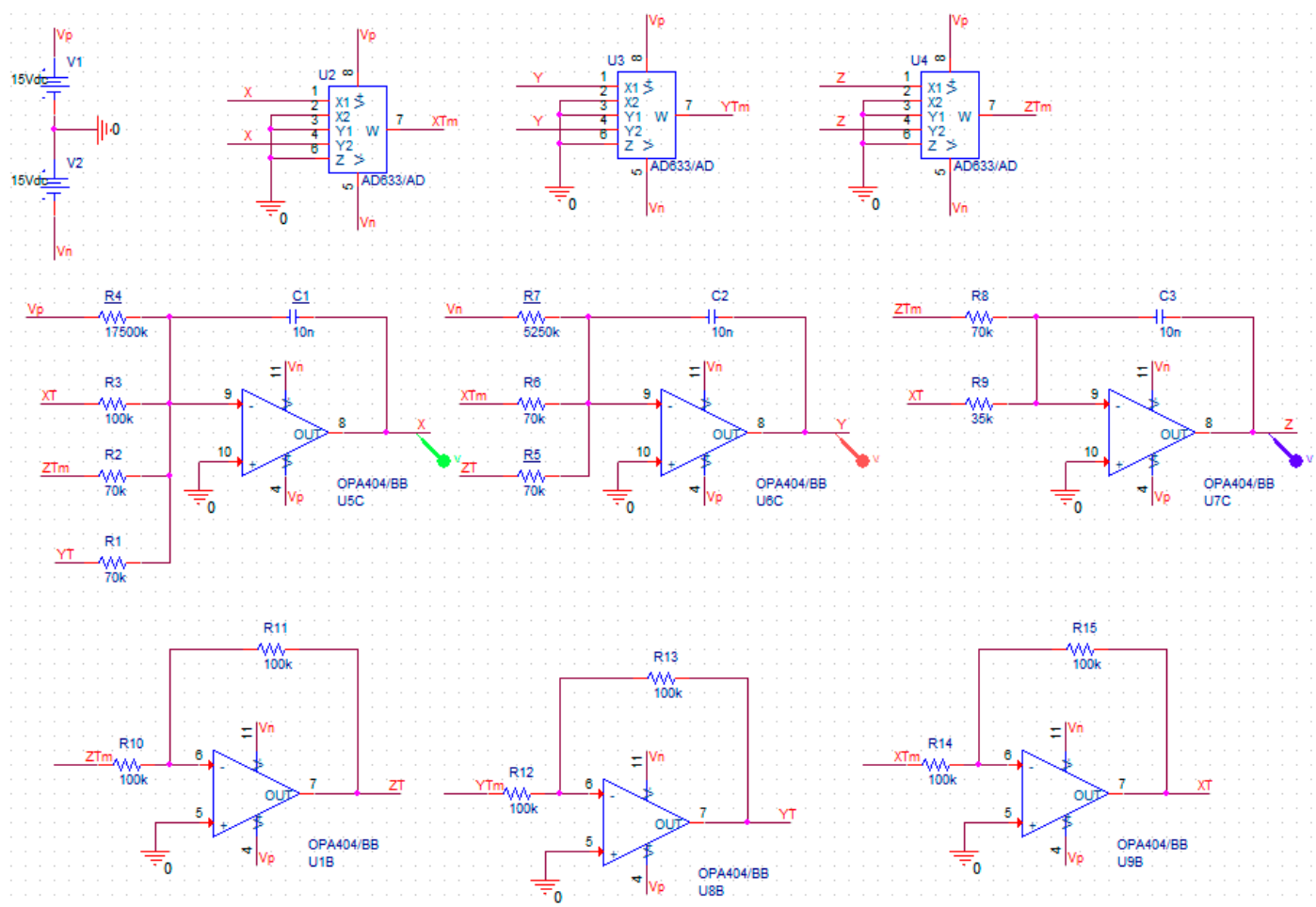

Figure 9. Schematic of the chaotic circuit.
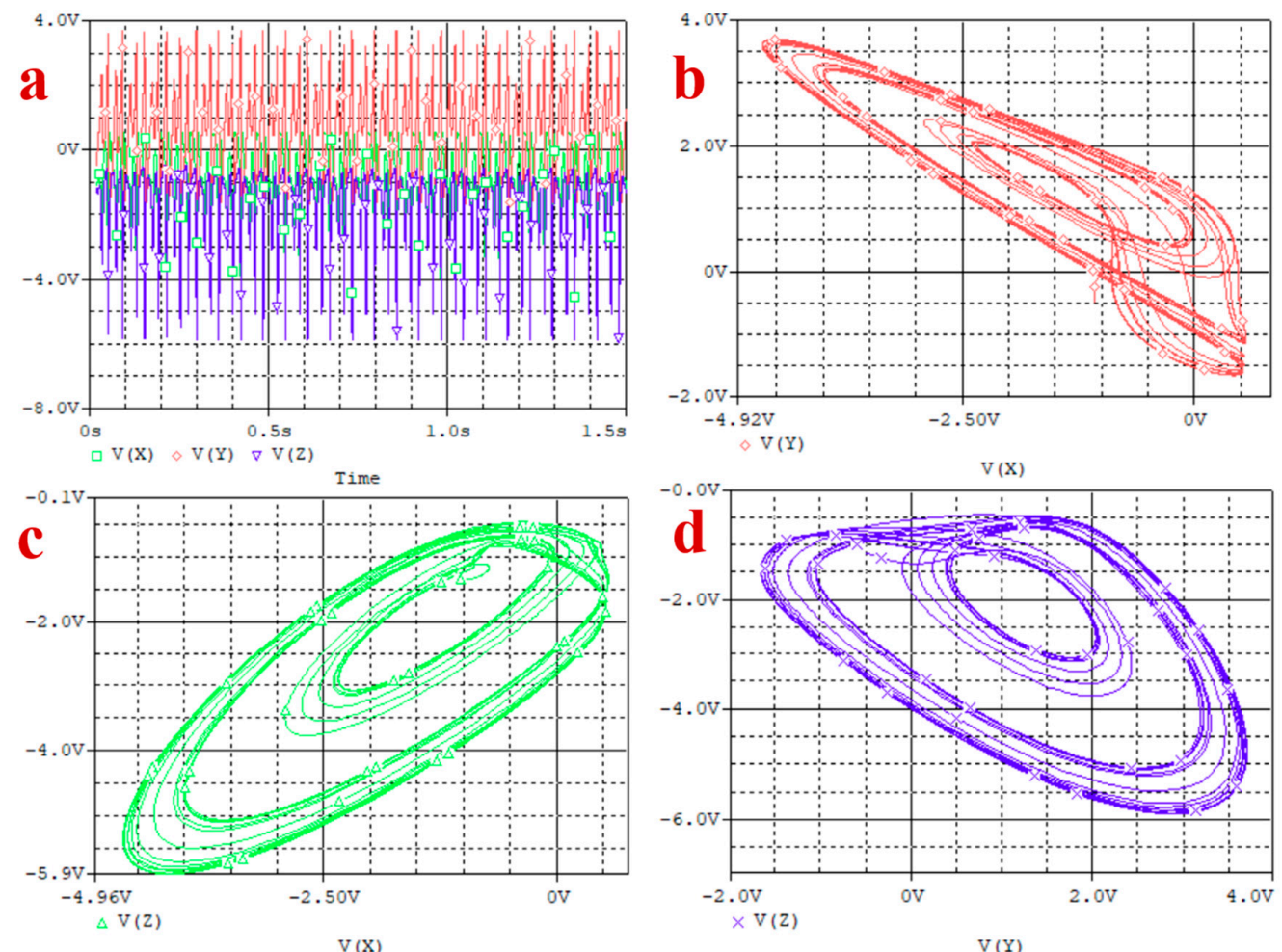

Figure 10. (a) time series of the chaotic circuit; the chaotic attractor in (b) $X-Y$ plane; (c) $X-Z$ plane; (d) $Y-Z$ plane. 


\section{Conclusions}

A novel quadratic chaotic oscillator was proposed here. The attractors of the oscillator were studied. Investigating the oscillator has shown the existence of eight equilibrium points, and none of them are stable; 1D and 2D bifurcation diagrams were studied to investigate the various dynamics of the oscillator. The results have shown the rich dynamics of the oscillator. LEs have revealed the types of dynamics. Studying bifurcation diagrams of the system by different initial values has shown coexisting attractors in different parameter regions. The basin of attractions was discussed in two planes. In addition, some of the multistable attractors were shown. Impulsive control was applied to the oscillator to force the chaotic dynamics approaches to the origin. The results have shown the high potential of this controller. Then the circuit of the oscillator was designed, which presents the feasibility of the chaotic dynamics. The complex dynamics of the oscillator make it a proper choice for random number generators and encryption applications.

Author Contributions: Conceptualization, D.V.; methodology, A.A.; software, H.N.; validation, S.J. and D.V.; investigation, A.A. and A.A.A.E.-L.; writing-original draft preparation, D.V., H.N. and A.A.A.E.-L.; writing-review and editing, A.A. and S.J.; supervision, S.J. and A.A.A.E.-L.; funding acquisition, D.V. All authors have read and agreed to the published version of the manuscript.

Funding: This work is partially funded by Centre for Nonlinear Systems, Chennai Institute of Technology, India vide funding number CIT/CNS/2021/RD/064.

Institutional Review Board Statement: Not applicable.

Informed Consent Statement: Not applicable.

Data Availability Statement: Not applicable.

Acknowledgments: Thanks to our families for their valuable and unconditional supports.

Conflicts of Interest: The authors declare no conflict of interest.

\section{References}

1. Li, C.; Yang, Y.; Du, J.; Chen, Z. A simple chaotic circuit with magnetic flux-controlled memristor. Eur. Phys. J. Spec. Top. 2021, 230, 1723-1736. [CrossRef]

2. Kamal, F.; Elsonbaty, A.; Elsaid, A. A novel fractional nonautonomous chaotic circuit model and its application to image encryption. Chaos Solitons Fractals 2021, 144, 110686. [CrossRef]

3. Ma, C.; Mou, J.; Xiong, L.; Banerjee, S.; Liu, T.; Han, X. Dynamical analysis of a new chaotic system: Asymmetric multistability, offset boosting control and circuit realization. Nonlinear Dyn. 2021, 103, 2867-2880. [CrossRef]

4. Bonny, T. Chaotic or hyper-chaotic oscillator? Numerical solution, circuit design, MATLAB HDL-coder implementation, VHDL code, security analysis, and FPGA realization. Circuits Syst. Signal Process. 2021, 40, 1061-1088.

5. Mathale, D.; Goufo, E.F.D.; Khumalo, M. Coexistence of multi-scroll chaotic attractors for a three-dimensional quadratic autonomous fractional system with non-local and non-singular kernel. Alex. Eng. J. 2021, 60, 3521-3538. [CrossRef]

6. Mammeri, M. A 2-D Discrete Cubic Chaotic Mapping with Symmetry: Una cartografía caótica cúbica discreta con simetría. South Fla. J. Dev. 2021, 2, 5111-5121. [CrossRef]

7. Chen, M.; Wang, Z.; Nazarimehr, F.; Jafari, S. A novel memristive chaotic system without any equilibrium point. Integration 2021, 79, 133-142. [CrossRef]

8. Wei, Z. Dynamical behaviors of a chaotic system with no equilibria. Phys. Lett. A 2011, 376, 102-108. [CrossRef]

9. Wang, X.; Chen, G. A chaotic system with only one stable equilibrium. Commun. Nonlinear Sci. Numer. Simul. 2012, 17, 1264-1272. [CrossRef]

10. Sambas, A.; Vaidyanathan, S.; Bonny, T.; Zhang, S.; Hidayat, Y.; Gundara, G.; Mamat, M. Mathematical Model and FPGA Realization of a Multi-Stable Chaotic Dynamical System with a Closed Butterfly-Like Curve of Equilibrium Points. Appl. Sci. 2021, 11, 788. [CrossRef]

11. Sambas, A.; Vaidyanathan, S.; Tlelo-Cuautle, E.; Abd-El-Atty, B.; El-Latif, A.A.A.; Guillén-Fernández, O.; Hidayat, Y.; Gundara, G. A 3-D multi-stable system with a peanut-shaped equilibrium curve: Circuit design, FPGA realization, and an application to image encryption. IEEE Access 2020, 8, 137116-137132. [CrossRef]

12. Rajagopal, K.; Duraisamy, P.; Tadesse, G.; Volos, C.; Nazarimehr, F.; Hussain, I. A fractional-order ship power system: Chaos and its dynamical properties. Int. J. Nonlinear Sci. Numer. Simul. 2021. [CrossRef] 
13. Nestor, T.; de Dieu, N.J.; Jacques, K.; Yves, E.J.; Iliyasu, A.M.; El-Latif, A.; Ahmed, A. A multidimensional hyperjerk oscillator: Dynamics analysis, analogue and embedded systems implementation, and its application as a cryptosystem. Sensors 2020, 20, 83. [CrossRef] [PubMed]

14. Ali, A.M.; Ramadhan, S.M.; Tahir, F.R. A Novel 2D—Grid of Scroll Chaotic Attractor Generated by CNN. Symmetry 2019, 11, 99. [CrossRef]

15. Lai, Q.; Chen, S. Generating multiple chaotic attractors from Sprott B system. Int. J. Bifurc. Chaos 2016, 26, 1650177. [CrossRef]

16. Yu, F.; Shen, H.; Zhang, Z.; Huang, Y.; Cai, S.; Du, S. Dynamics analysis, hardware implementation and engineering applications of novel multi-style attractors in a neural network under electromagnetic radiation. Chaos Solitons Fractals 2021, 152, 111350. [CrossRef]

17. Tsafack, N.; Sankar, S.; Abd-El-Atty, B.; Kengne, J.; Jithin, K.; Belazi, A.; Mehmood, I.; Bashir, A.K.; Song, O.-Y.; El-Latif, A.A.A. A new chaotic map with dynamic analysis and encryption application in internet of health things. IEEE Access 2020, 8, 137731-137744. [CrossRef]

18. Amin, M.; Abd El-Latif, A.A. Efficient modified RC5 based on chaos adapted to image encryption. J. Electron. Imaging 2010, 19, 013012. [CrossRef]

19. Abd El-Latif, A.A.; Yan, X.; Li, L.; Wang, N.; Peng, J.-L.; Niu, X. A new meaningful secret sharing scheme based on random grids, error diffusion and chaotic encryption. Opt. Laser Technol. 2013, 54, 389-400. [CrossRef]

20. Li, L.; Abd-El-Atty, B.; El-Latif, A.A.A.; Ghoneim, A. Quantum color image encryption based on multiple discrete chaotic systems. In Proceedings of the 2017 Federated Conference on Computer Science and Information Systems (FedCSIS), Prague, Czech Republic, 3-6 September 2017.

21. Abd el-Latif, A.A.; Abd-el-Atty, B.; Amin, M.; Iliyasu, A.M. Quantum-inspired cascaded discrete-time quantum walks with induced chaotic dynamics and cryptographic applications. Sci. Rep. 2020, 10, 1930. [CrossRef]

22. Abd EL-Latif, A.A.; Abd-El-Atty, B.; Abou-Nassar, E.M.; Venegas-Andraca, S.E. Controlled alternate quantum walks based privacy preserving healthcare images in internet of things. Opt. Laser Technol. 2020, 124, 105942. [CrossRef]

23. Zhang, R.; Yu, L.; Jiang, D.; Ding, W.; Song, J.; He, K.; Ding, Q. A Novel Plaintext-Related Color Image Encryption Scheme Based on Cellular Neural Network and Chen's Chaotic System. Symmetry 2021, 13, 393. [CrossRef]

24. Veeman, D.; Natiq, H.; Al-Saidi, N.M.; Rajagopal, K.; Jafari, S.; Hussain, I. A New Megastable Chaotic Oscillator with Blinking Oscillation terms. Complexity 2021, 2021, 5518633. [CrossRef]

25. Ji'e, M.; Yan, D.; Wang, L.; Duan, S. Hidden Attractor and Multistability in a Novel Memristor-Based System Without Symmetry. Int. J. Bifurc. Chaos 2021, 31, 2150168. [CrossRef]

26. Lai, Q. A Unified Chaotic System with Various Coexisting Attractors. Int. J. Bifurc. Chaos 2021, 31, 2150013. [CrossRef]

27. Pisarchik, A.N.; Jaimes-Reátegui, R.; Rodríguez-Flores, C.; García-López, J.; Huerta-Cuéllar, G.; Martín-Pasquín, F. Secure chaotic communication based on extreme multistability. J. Frankl. Inst. 2021, 358, 2561-2575. [CrossRef]

28. Chen, B.; Rajagopal, K.; Hamarash, I.I.; Karthikeyan, A.; Hussain, I. Simple megastable oscillators with different types of attractors; tori, chaotic and hyperchaotic ones. Eur. Phys. J. Spec. Top. 2020, 229, 1155-1161. [CrossRef]

29. Meli, M.I.T.; Yemélé, D.; Leutcho, G.D. Dynamical analysis of series hybrid electric vehicle powertrain with torsional vibration: Antimonotonicity and coexisting attractors. Chaos Solitons Fractals 2021, 150, 111174. [CrossRef]

30. Tametang Meli, M.I.; Leutcho, G.D.; Yemele, D. Multistability analysis and nonlinear vibration for generator set in series hybrid electric vehicle through electromechanical coupling. Chaos Interdiscip. J. Nonlinear Sci. 2021, 31, 073126. [CrossRef]

31. Chen, M.; Wang, C.; Bao, H.; Ren, X.; Bao, B.; Xu, Q. Reconstitution for interpreting hidden dynamics with stable equilibrium point. Chaos Solitons Fractals 2020, 140, 110188. [CrossRef]

32. Zhang, H.; Sun, K.; He, S. A fractional-order ship power system with extreme multistability. Nonlinear Dyn. 2021, 106, 1027-1040. [CrossRef]

33. Wang, N.; Zhang, G.; Kuznetsov, N.V.; Bao, H. Hidden attractors and multistability in a modified Chua's circuit. Commun. Nonlinear Sci. Numer. Simul. 2021, 92, 105494. [CrossRef]

34. Bao, H.; Hua, Z.; Li, H.; Chen, M.; Bao, B. Discrete Memristor Hyperchaotic Maps. IEEE Trans. Circuits Syst. I Regul. Pap. 2021, 68, 4534-4544. [CrossRef]

35. Bao, B.; Zhu, Y.; Ma, J.; Bao, H.; Wu, H.; Chen, M. Memristive neuron model with an adapting synapse and its hardware experiments. Sci. China Technol. Sci. 2021, 64, 1107-1117. [CrossRef]

36. Hua, M.; Wu, H.; Xu, Q.; Chen, M.; Bao, B. Asymmetric memristive Chua's chaotic circuits. Int. J. Electron. 2021, 108, 1106-1123. [CrossRef]

37. Gu, J.; Li, C.; Lei, T.; He, S.; Min, F. A memristive chaotic system with flexible attractor growing. Eur. Phys. J. Spec. Top. 2021, 230, 1695-1708. [CrossRef]

38. Peng, Y.; He, S.; Sun, K. Chaos in the discrete memristor-based system with fractional-order difference. Results Phys. 2021, 24, 104106. [CrossRef]

39. Huang, L.-L.; Liu, S.; Xiang, J.-H.; Wang, L.-Y. Design and multistability analysis of five-value memristor-based chaotic system with hidden attractors. Chin. Phys. B 2021, 30, 100506. [CrossRef]

40. Zhao, Y.; Li, X.; Rao, R. Synchronization of nonidentical complex dynamical networks with unknown disturbances via observerbased sliding mode control. Neurocomputing 2021, 454, 441-447. [CrossRef] 
41. Zhou, Z.-X.; Grebogi, C.; Ren, H.-P. Parameter impulse control of chaos in crystal growth process. J. Cryst. Growth 2021, 563, 126079. [CrossRef]

42. Mahmoud, E.E.; Higazy, M.; Althagafi, O.A. A novel strategy for complete and phase robust synchronizations of chaotic nonlinear systems. Symmetry 2020, 12, 1765. [CrossRef]

43. Boccaletti, S.; Grebogi, C.; Lai, Y.-C.; Mancini, H.; Maza, D. The control of chaos: Theory and applications. Phys. Rep. 2000, 329, 103-197. [CrossRef]

44. Yassen, M. Chaos control of Chen chaotic dynamical system. Chaos Solitons Fractals 2003, 15, 271-283. [CrossRef]

45. Zhou, S.-S.; Jahanshahi, H.; Din, Q.; Bekiros, S.; Alcaraz, R.; Alassafi, M.O.; Alsaadi, F.E.; Chu, Y.-M. Discrete-time macroeconomic system: Bifurcation analysis and synchronization using fuzzy-based activation feedback control. Chaos Solitons Fractals 2021, 142, 110378. [CrossRef]

46. Fu, S.; Liu, Y.; Ma, H.; Du, Y. Control chaos to different stable states for a piecewise linear circuit system by a simple linear control Chaos Solitons Fractals 2020, 130, 109431. [CrossRef]

47. Pham, V.-T.; Vaidyanathan, S.; Volos, C.; Jafari, S.; Alsaadi, F.E.; Alsaadi, F.E. Chaos in a simple snap system with only one nonlinearity, its adaptive control and real circuit design. Arch. Control. Sci. 2019, 29, 73-96.

48. Pyragas, K. Delayed feedback control of chaos. Philos. Trans. R. Soc. A Math. Phys. Eng. Sci. 2006, 364, 2309-2334. [CrossRef]

49. Wu, S.; Li, X.; Ding, Y. Saturated impulsive control for synchronization of coupled delayed neural networks. Neural Netw. 2021, 141, 261-269. [CrossRef]

50. Peng, D.; Li, X.; Rakkiyappan, R.; Ding, Y. Stabilization of stochastic delayed systems: Event-triggered impulsive control. Appl. Math. Comput. 2021, 401, 126054. [CrossRef]

51. Wang, M.; Wu, S.; Li, X. Event-triggered delayed impulsive control for nonlinear systems with applications. J. Frankl. Inst. 2021, 358, 4277-4291. [CrossRef]

52. Li, X.; Li, P. Input-to-state stability of nonlinear systems: Event-triggered impulsive control. IEEE Trans. Autom. Control 2021, 1-7. [CrossRef]

53. Zhang, X.; Li, X.; Han, X. Design of hybrid controller for synchronization control of Chen chaotic system. J. Nonlinear Sci. Appl. 2017, 10, 3320-3327. [CrossRef]

54. Li, X.; Rakkiyappan, R. Impulsive controller design for exponential synchronization of chaotic neural networks with mixed delays. Commun. Nonlinear Sci. Numer. Simul. 2013, 18, 1515-1523. [CrossRef]

55. Leutcho, G.D.; Kengne, J.; Kengne, L.K.; Akgul, A.; Pham, V.-T.; Jafari, S. A novel chaotic hyperjerk circuit with bubbles of bifurcation: Mixed-mode bursting oscillations, multistability, and circuit realization. Phys. Scr. 2020, 95, 075216. [CrossRef]

56. Yu, F.; Shen, H.; Liu, L.; Zhang, Z.; Huang, Y.; He, B.; Cai, S.; Song, Y.; Yin, B.; Du, S. CCII and FPGA realization: A multistable modified fourth-order autonomous Chua's chaotic system with coexisting multiple attractors. Complexity 2020, 2020, 5212601. [CrossRef]

57. Li, C.; Wei, Z.; Zhang, W. Periodic solutions and circuit design of chaos in a unified stretch-twist-fold flow. Eur. Phys. J. Spec. Top. 2021, 230, 1971-1978. [CrossRef]

58. Kengne, J.; Kengne, L.K.; Chedjou, J.C.; Nosirov, K. A simple anti-parallel diodes based chaotic jerk circuit with arcsinh function: Theoretical analysis and experimental verification. Analog Integr. Circuits Signal Process. 2021, 108, 597-623. [CrossRef]

59. Hu, H.; Cao, Y.; Xu, J.; Ma, C.; Yan, H. An image compression and encryption algorithm based on the fractional-order simplest chaotic circuit. IEEE Access 2021, 9, 22141-22155. [CrossRef]

60. Wan, Q.; Zhou, Z.; Ji, W.; Wang, C.; Yu, F. Dynamic analysis and circuit realization of a novel no-equilibrium 5D memristive hyperchaotic system with hidden extreme multistability. Complexity 2020, 2020, 7106861. [CrossRef]

61. Lai, Q.; Kuate, P.D.K.; Liu, F.; Iu, H.H.-C. An extremely simple chaotic system with infinitely many coexisting attractors. IEEE Trans. Circuits Syst. II Express Briefs 2019, 67, 1129-1133. [CrossRef]

62. Lai, Q.; Wan, Z.; Kengne, L.K.; Kuate, P.D.K.; Chen, C. Two-memristor-based chaotic system with infinite coexisting attractors IEEE Trans. Circuits Syst. II Express Briefs 2020, 68, 2197-2201. [CrossRef]

63. Yu, F.; Shen, H.; Zhang, Z.; Huang, Y.; Cai, S.; Du, S. A new multi-scroll Chua's circuit with composite hyperbolic tangent-cubic nonlinearity: Complex dynamics, Hardware implementation and Image encryption application. Integration 2021, 81, 71-83. [CrossRef]

64. Lai, Q.; Wan, Z.; Kuate, P.D.K. Modelling and circuit realisation of a new no-equilibrium chaotic system with hidden attractor and coexisting attractors. Electron. Lett. 2020, 56, 1044-1046. [CrossRef]

65. Li, C.; Lei, T.; Wang, X.; Chen, G. Dynamics editing based on offset boosting. Chaos Interdiscip. J. Nonlinear Sci. 2020, $30,063124$. [CrossRef]

66. Li, C.; Wang, X.; Chen, G. Diagnosing multistability by offset boosting. Nonlinear Dyn. 2017, 90, 1335-1341. [CrossRef]

67. Sun, J.; Zhang, Y. Impulsive control of Lorenz systems. In Proceedings of the Fifth World Congress on Intelligent Control and Automation (IEEE Cat. No. 04EX788), Hangzhou, China, 15-19 June 2004.

68. Zhang, Y.; Sun, J. Controlling chaotic Lu systems using impulsive control. Phys. Lett. A 2005, 342, 256-262. [CrossRef] 